A Novel Approach of Passive Localization for Indoor Positioning

Martin Schmidhammer and Christian Gentner 


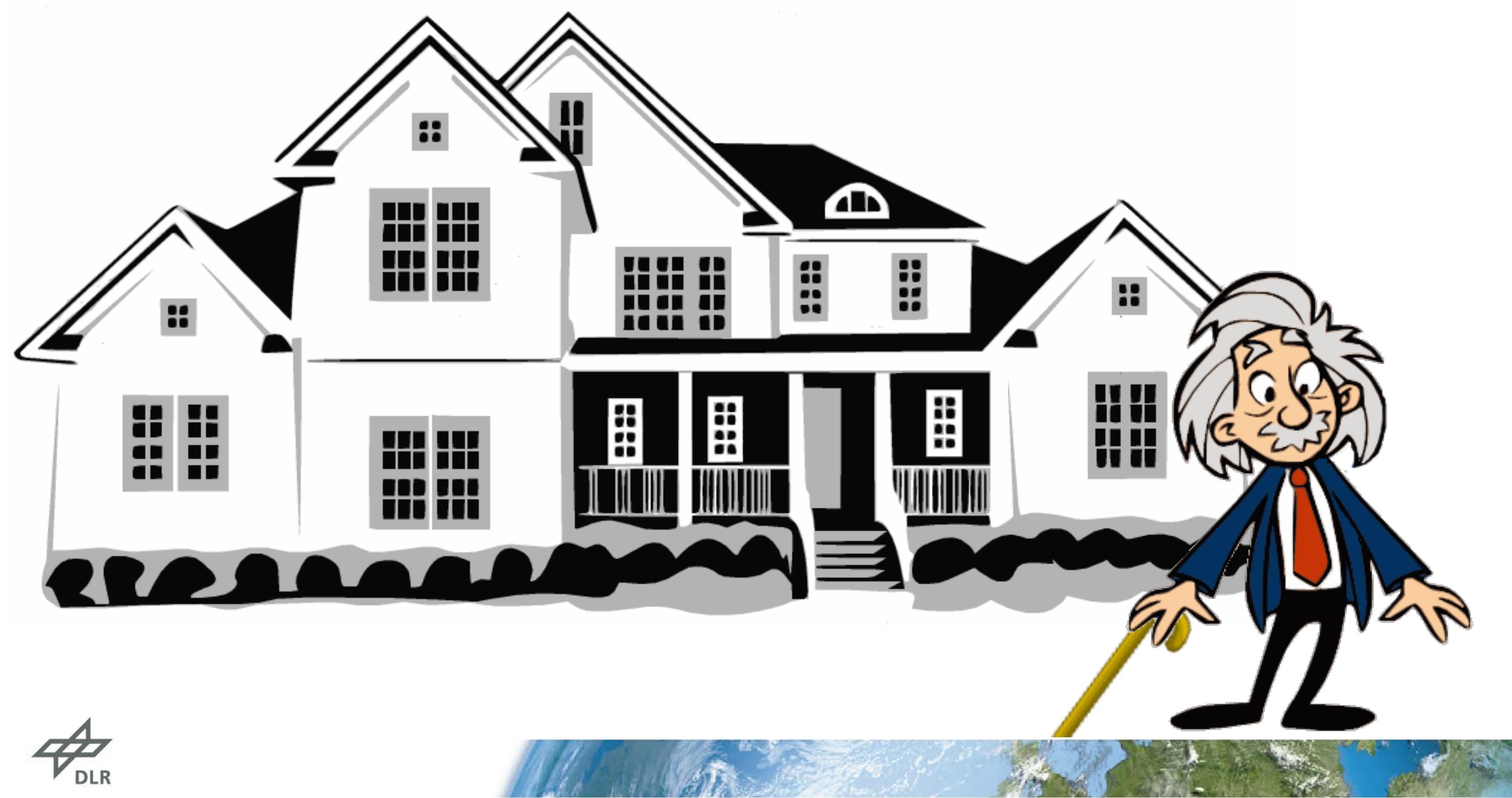




\section{Devide-free loøalization and tracking}

- Line-of-sight (LOS) links between wireless communication nodes

- Recejved signal strength-depending $/$ n

- path loss

- \$hadowing from static environment

- multipath fading

- shatowing-trom dynamic environment

- Bayesian filtering for localization and tracking

- Unambiguous localization requires dense network of wireless communication nodes
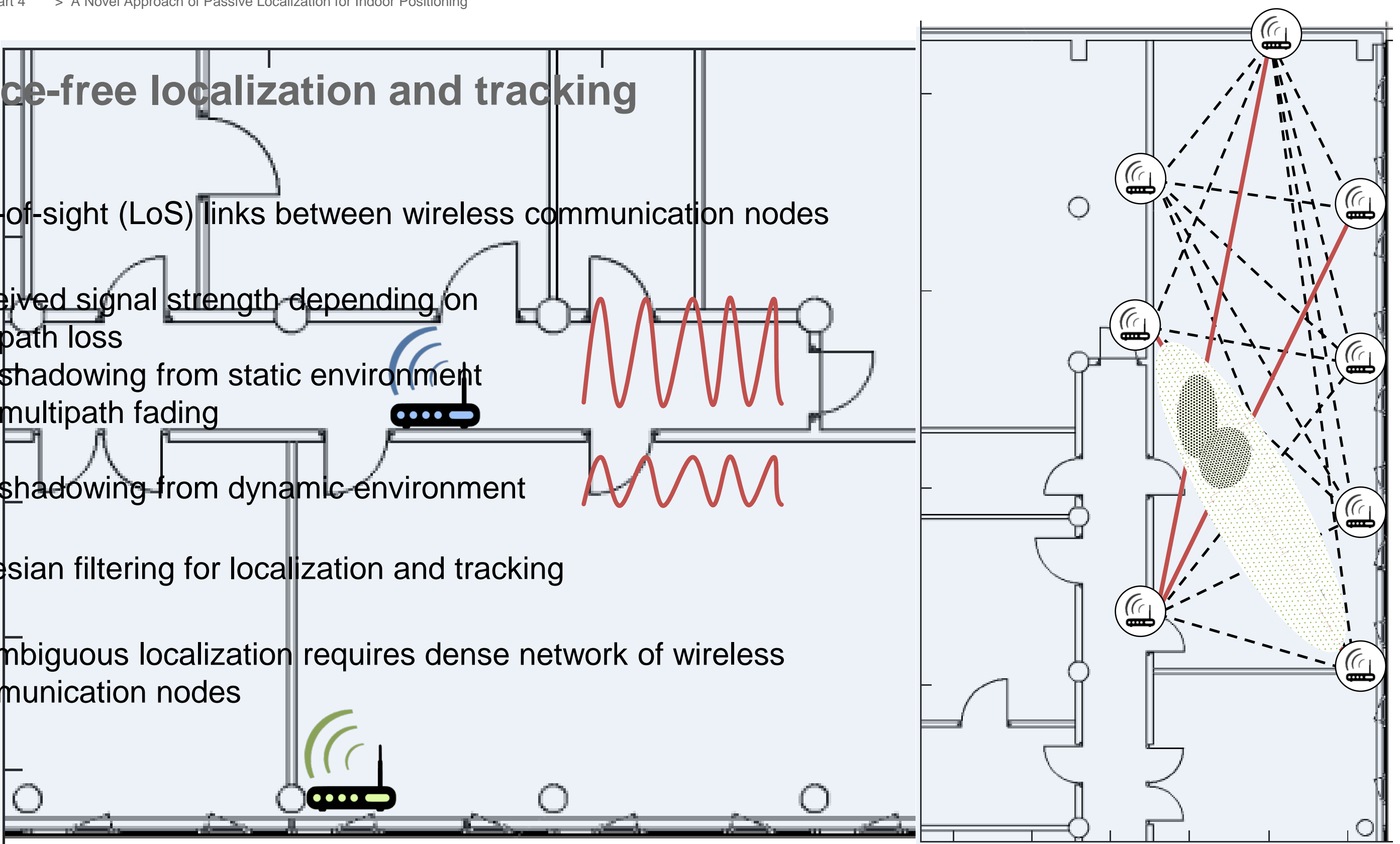


\section{Device-free localization and tracking} Direct links only!?

Measurement hardware
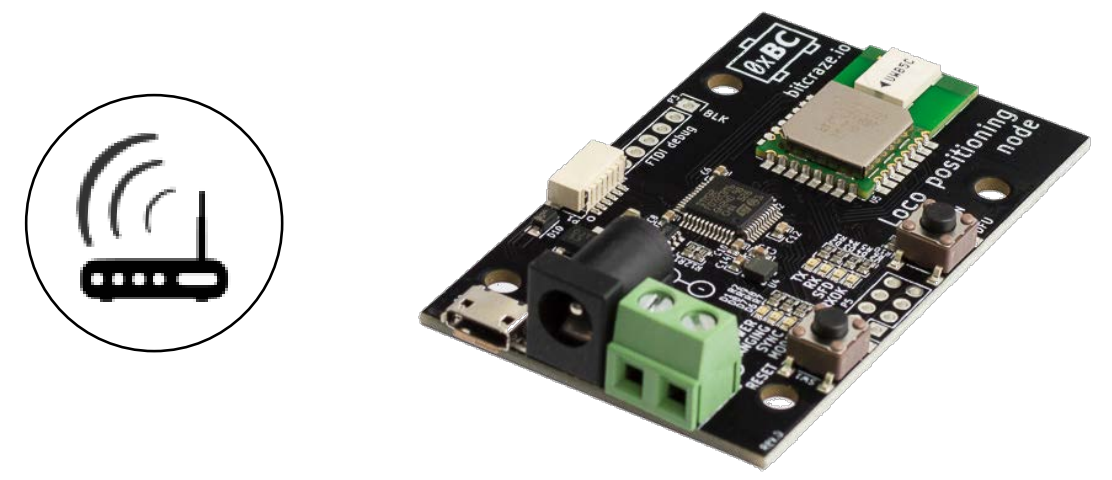

decaWave DWM1000 chip

- IEEE 802.15.4-2011 UltraWideband compliant

- $500 \mathrm{MHz}$ bandwidth

- Low-cost transceiver

- Low-power consumption

- Channel impulse response (CIR) accessable

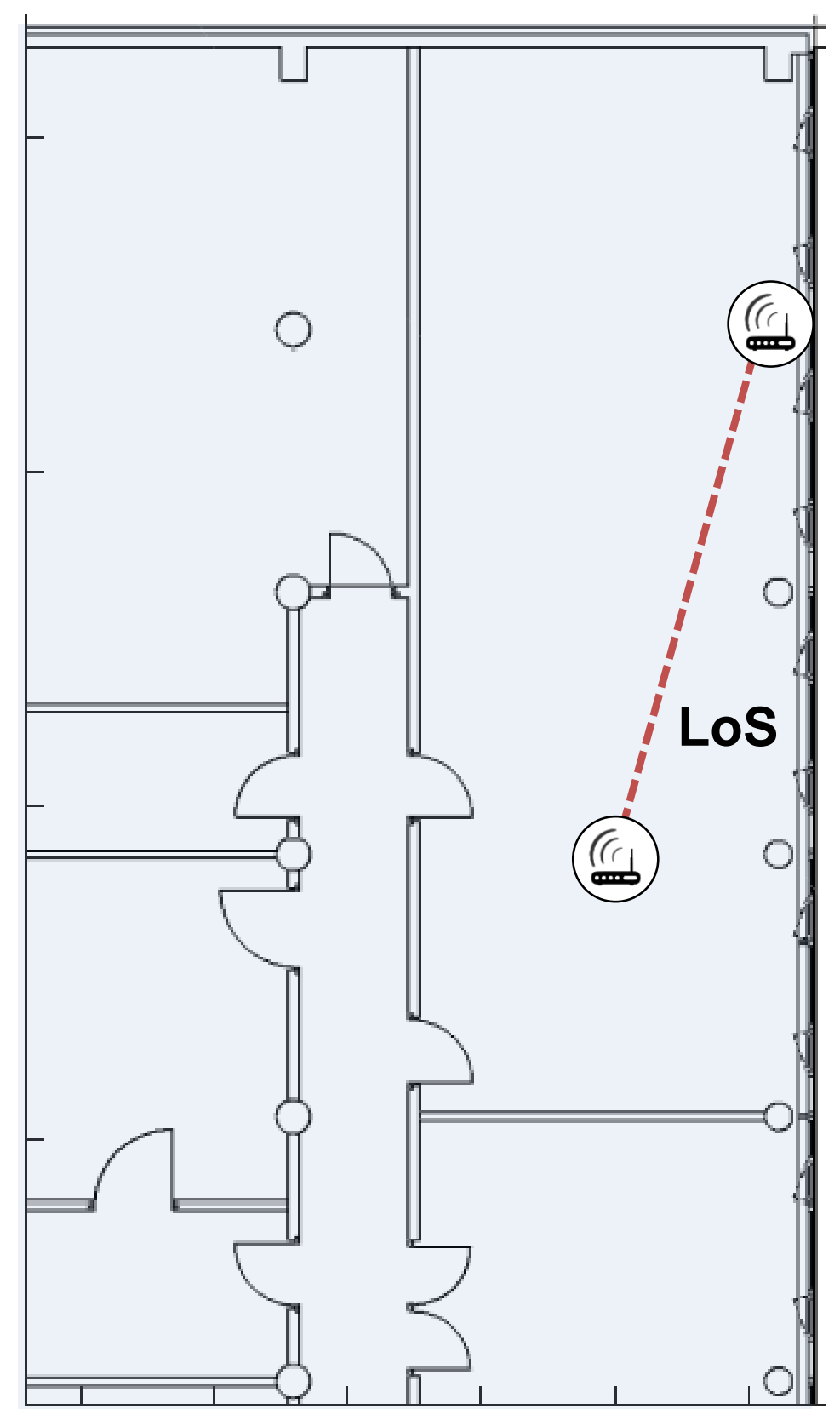




\section{Device-free localization and tracking}

\section{Direct links only!?}

Static multipath components (MPC) from reflection and scattering

\section{LoS link}

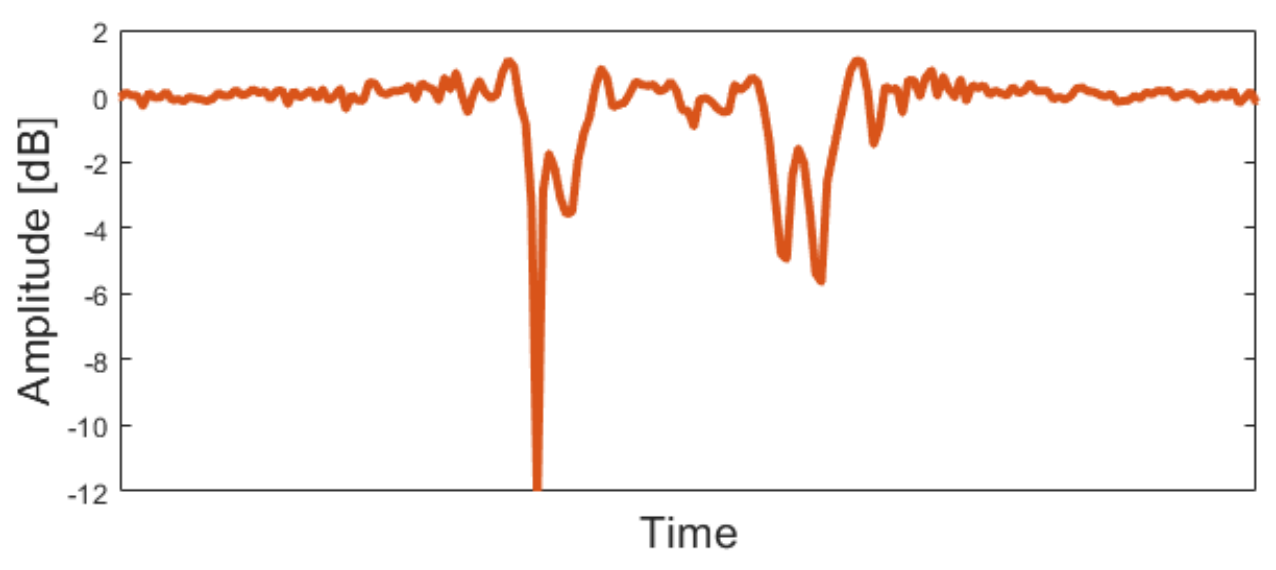

MPC link
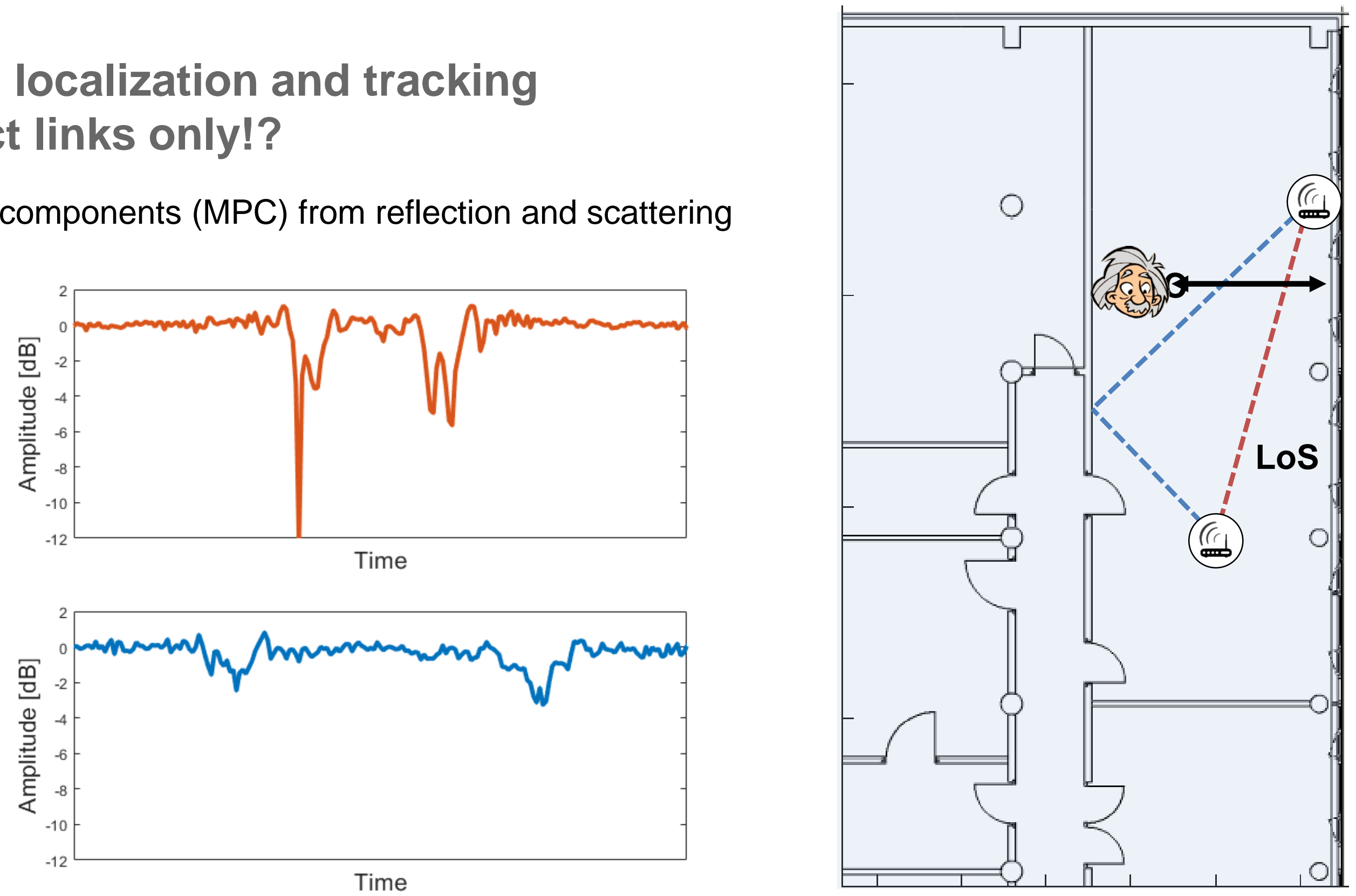


\section{Device-free localization and tracking} Multipath-enhanced!

Preprocessing for each pair of transmitter and receiver

\section{Calibration}
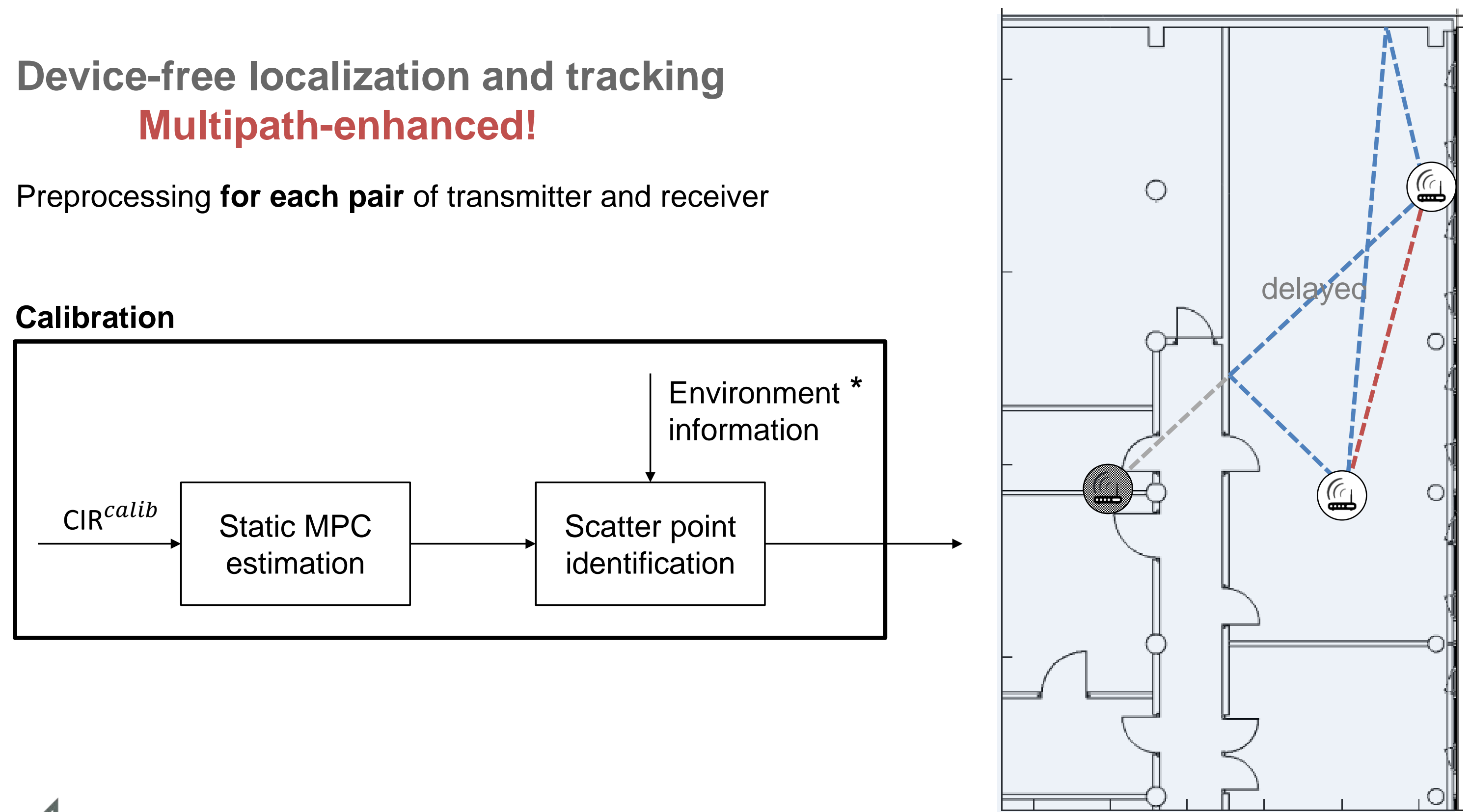


\section{Device-free localization and tracking} Multipath-enhanced!

Preprocessing for each pair of transmitter and receiver
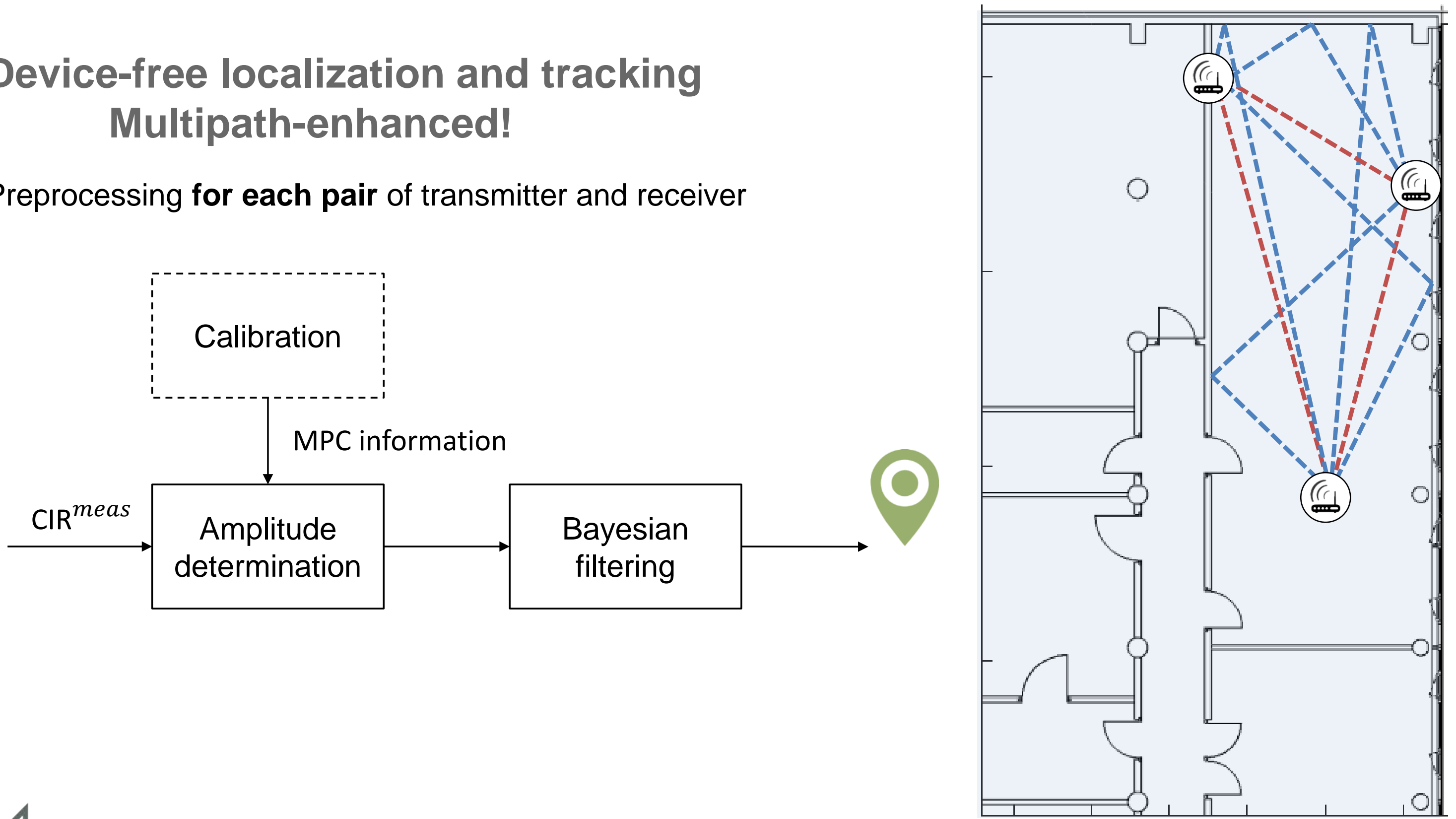
Device-free localization and tracking Multipath-enhanced!

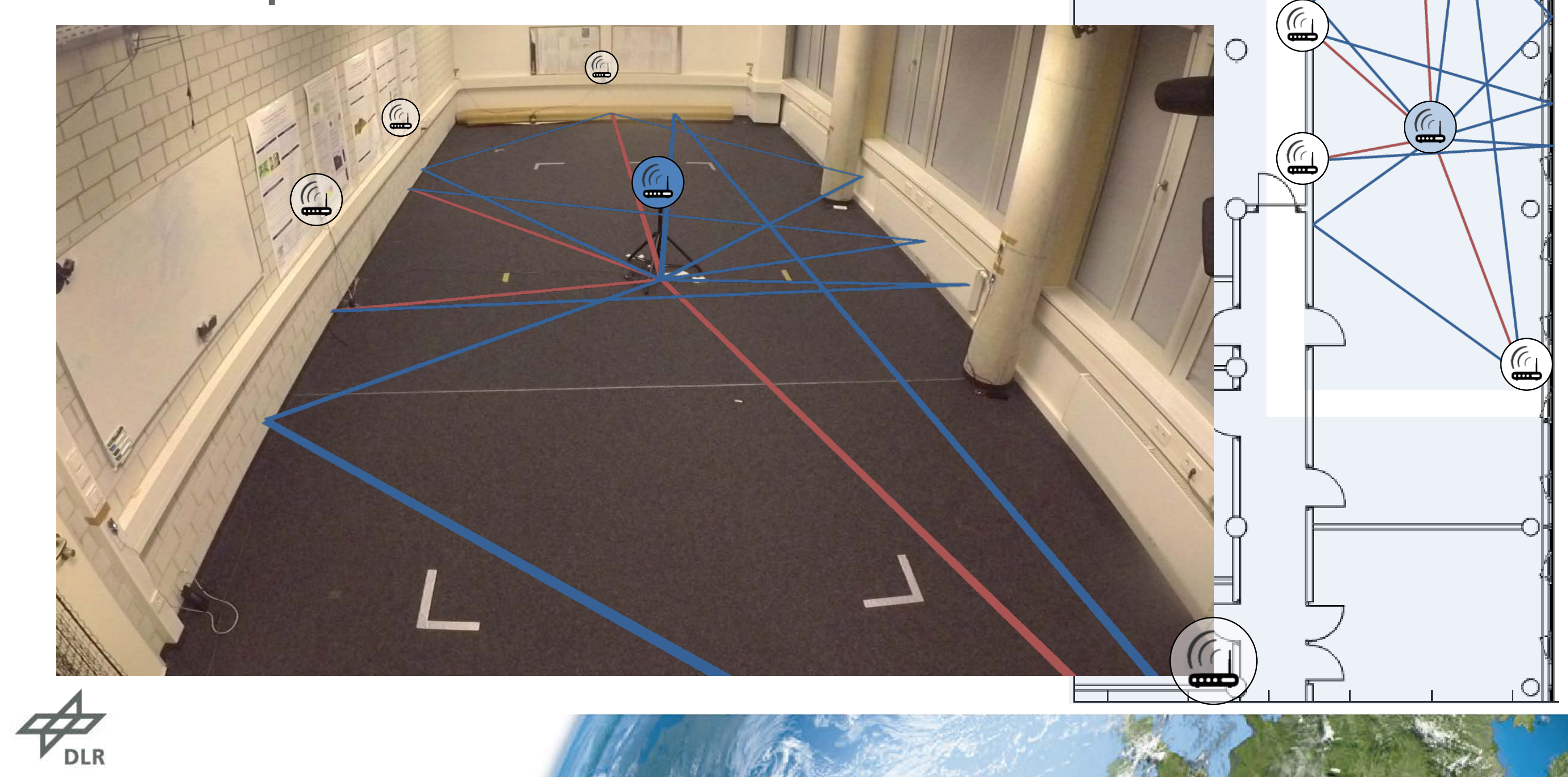


Device-free localization and tracking Multipath-enhanced!

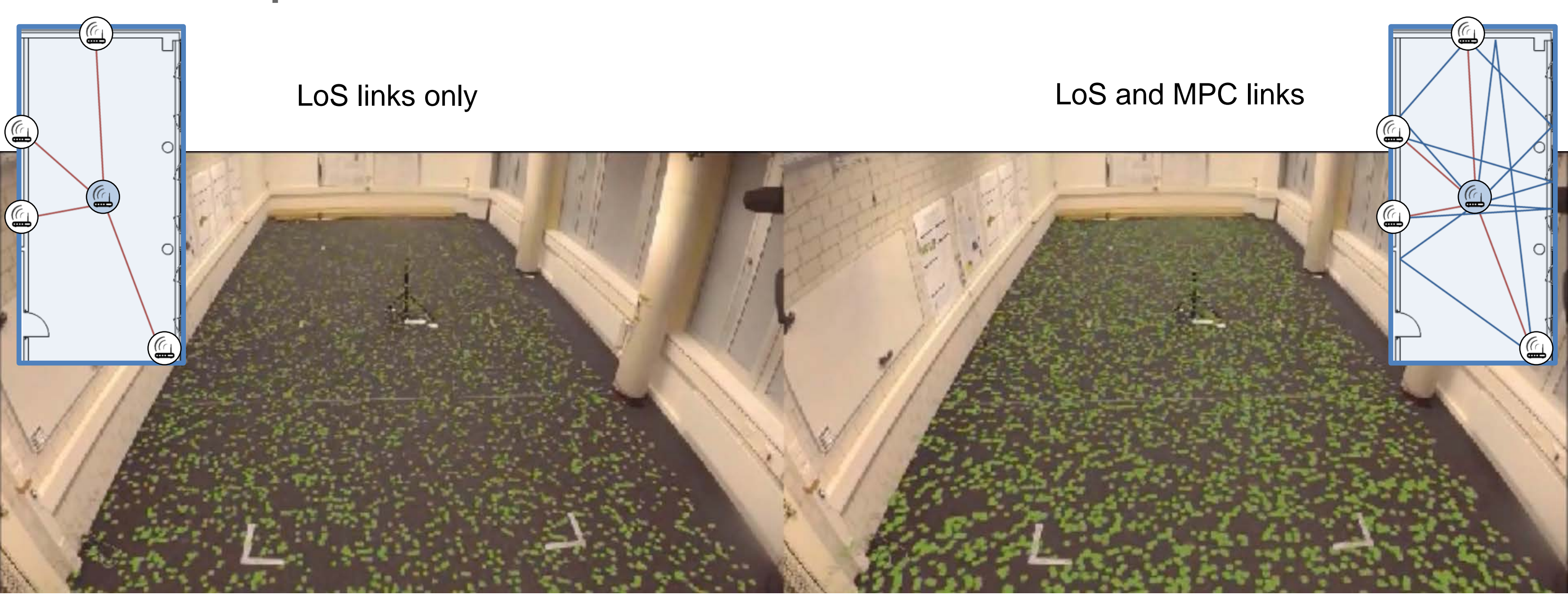




\section{Device-free localization and tracking} Multipath-enhanced!
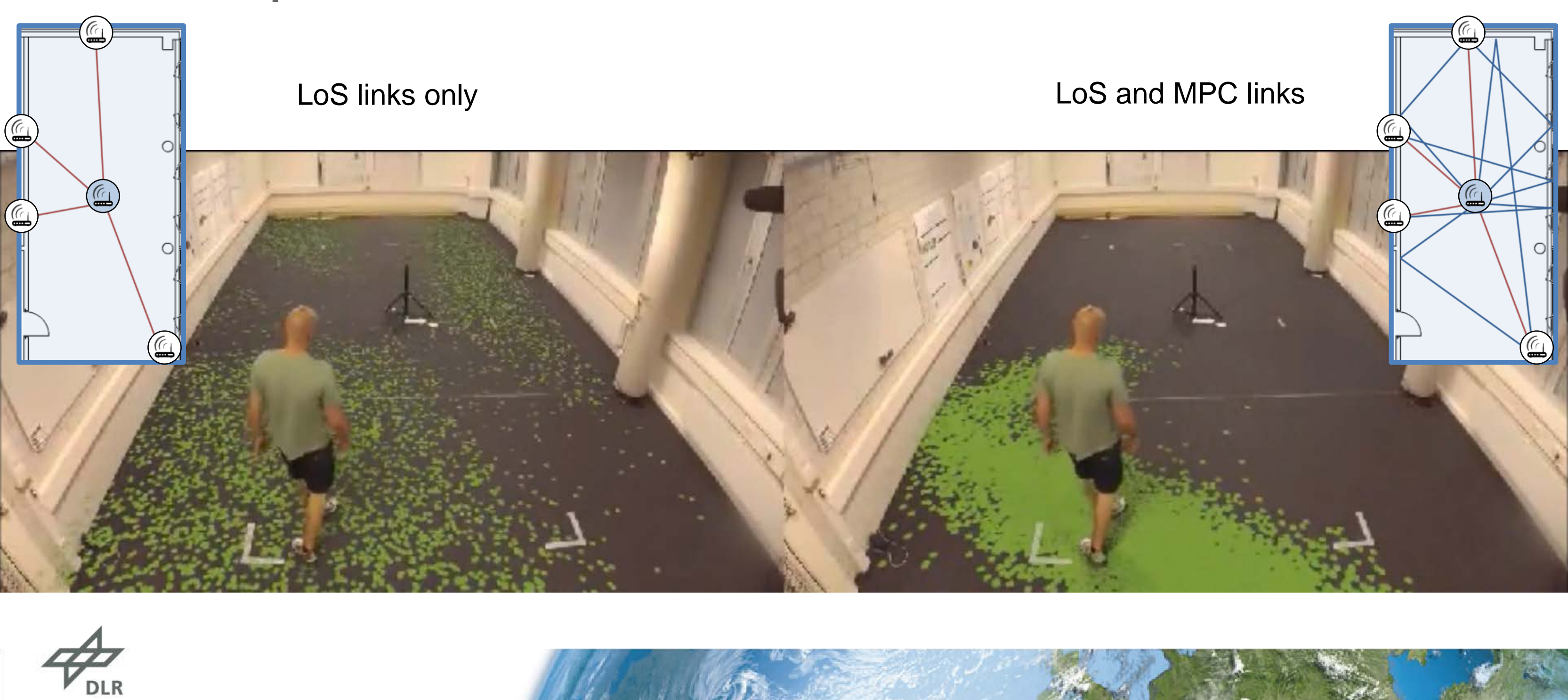


\section{Device-free localization and tracking} Multipath-enhanced!

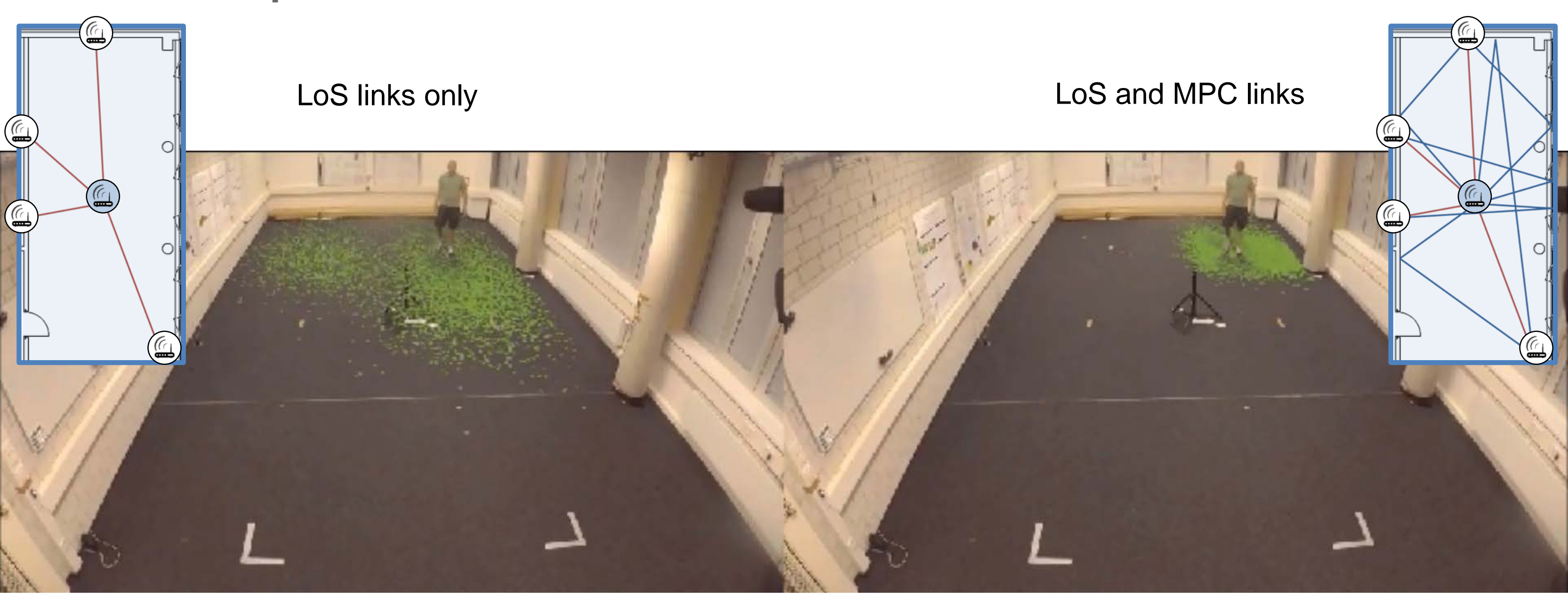




\section{Summary - Multipath-enhanced Device-free Localization and Tracking}

- Multipath propagation enhances device-free localization!

- Low-cost UltraWideband nodes are sufficient

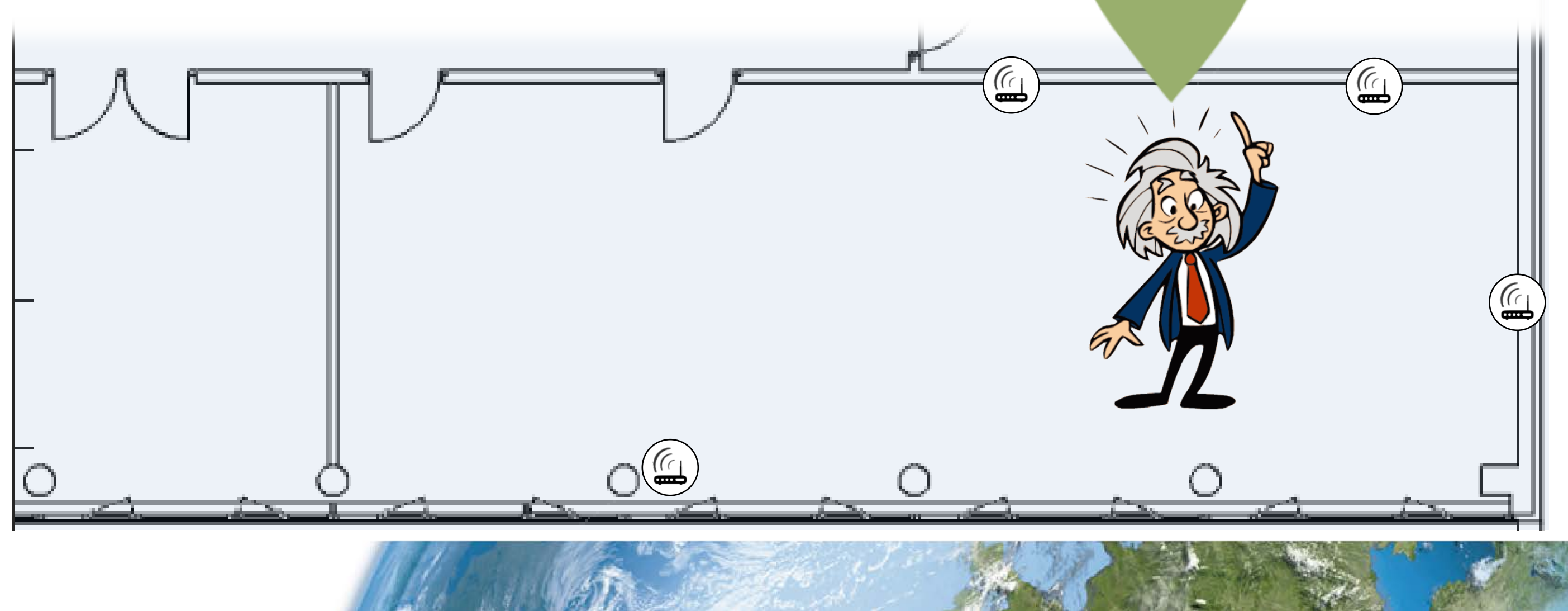

